\title{
MIN PREVALENCE OF ADVERSE EVENTS DURING TRANSPORT OF CRITICALLY ILL PATIENTS FROM THE EMERGENCY DEPARTMENT TO THE INTENSIVE CARE UNIT
}

\author{
Isti Wulandari*, Kuswantoro Rusca Putra, Tony Suharsono \\ Master Program in Nursing, Faculty of Medicine, Universitas Brawijaya, Malang, Indonesia \\ *Corresponding Author’s E-mail: istiwulandrsdm@yahoo.com
}

\begin{abstract}
Background: The process of Intra Hospital Transports (IHTs) of critically ill patients is at high risk of changing patient conditions. Emergency transportation causes complications and may affect patient safety. This study aims to describe the prevalence of adverse events during the transport of critically ill patients from the Emergency Department (ED) to the Intensive Care Unit. Method: This study applied an analytic observational design with a prospective cohort approach. The study examined 151 emergency patients. The inclusion criteria are patients aged $>16$ years and the issued decision to transfer the patients to the Intensive Care Unit at levels 2 and 3. Results: From 151 observed-transfer processes, $119(78.8 \%)$ respondents experienced adverse events. Among them 54 (45.5\%) were non-physiological cases, 33 (27.7\%) physiological, and $32(26.8 \%)$ combination of physiological and non-physiological adverse events. Most of the physiological adverse events were nausea (12 or $13.3 \%$ ), while most non-physiological adverse events were temporary cessation of therapy in the course of 65 (57\%). There is a significant relationship among age $(p=0.012, r=0.351)$, sex $(p=0.019, r=$ 0.249 ), suitability of transfer companion ( $p=0.005, r=0.281$ ) with the adverse events during the transport of critically ill patients from the Emergency Department to the Intensive Care Unit. Conclusion: Furthermore, risk management is required to reduce the complication at the time of transfer. During the transfer procedure continuous intravenous access must be ensured to minimize risk.
\end{abstract}

Keywords: Adverse Events, Intra-Hospital Transport, Critically Ill Patients

\section{INTRODUCTION}

The transport of patients is an inseparable part of service in the ED (Salt et al., 2018). Transport of patients between wards in the hospital aim to sustain patient care may result in high risk of adverse events (AEs) (Bergman et al., 2017). The actions taken in the ED may affect the safety of critical patients before being transferred to the Intensive Care Unit (Jiang et al., 2016).

The situations in the emergency rooms that are vulnerable, overcrowded along with limited resources make the transfer of patients from the emergency room more complex, varied, and hazardous (Choi et al., 2012; Farnoosh et al., 2018). Overcrowding of patient entailed by complex severity and its characteristics to work in the environment that races against time, causes of AEs in the Emergency Department (Stang et al., 2013). The transport of patients in unstable conditions may raise complications and risk patient safety (Decrucq et al., 2013; Harish et al., 2016).

Adverse events during the transfer of critically ill patients in the hospital are related to patient physiological changes (44.1\%), transfer of equipment was $23.5 \%$ and the staff was 19.7\% (Gimenez et al., 2017). Most of the adverse events related to the patient's clinical condition are the circulatory system $(40 \%)$, the respiratory system $(30 \%)$ and nervous system (25\%) (Tolentino et al., 2018). Meanwhile, minor incidents related to patients anxiety $(15 \%)$, agitation $(11.1 \%)$, and pain or discomfort (1\% - 6.1\%) (Jia et al., 2016; Jones et al., 2016).

A nurse is one of the professional medical workers 
that accompanies in transporting the patients (Kue et al., 2011). Research shows that IHTs of patients is a burden for nurses and will disrupt the workflow if it is not prepared properly (Jennings et al., 2013). Nurses consider patient transport as an unsafe and stressful task (Ringdal et al., 2016).

This study aims to determine the adverse events during the transfer of critically ill patients from the emergency room to the Intensive Care Unit in a hospital in Central Java.

\section{METHODOLOGY}

This quantitative study applied an analytic observational design with a prospective cohort approach. Researchers followed the process of transferring patients from the ED to the Intensive Care Unit. The population of this study consisted of all patients in ED with 2 or 3 transfer levels. The sample in this study consisted of 151 transport process of ED patients to the Intensive Care Unit in one of the general hospitals in Central Java. The study was conducted on January 5-31, 2020. The researcher was assisted by 2 enumerators who had carried out the interrater reliability test with a result of kappa $=1$. The sampling technique was the consecutive sampling technique. The inclusion criteria are emergency patients aged $>16$-years-old and eligible for transfer to Intensive Care Units level 2 and 3. The exclusion criteria are patients who died or were referred before transfer. Adverse events during the transport of patients were categorized into 4 groups namely physiological AEs, non-physiological AEs, combined AEs (physiological and non-physiological), and no AEs. The parameters of unexpected events during the transfers were based on the model developed by Jones et al., (2016). The instrument in this study used an observation sheet that had been tested by expert judgment. The data were processed using SPSS version 16. The descriptive data are presented in the form of frequencies and percentages. The bivariate test takes Cramer's V.

This study has received ethical clearance from the Health Research Ethics Omission at one of Regional Public Hospitals in Central Java, Number. 1.418/XII/ HREC/2019. The approval was given from the study site. Every respondent was informed about the objectives, benefits, and research procedure. The information was given to the patient and family. The willingness of the respondents in this study had no compulsion.

\section{RESULTS}

The prevalence of AEs during the transport of critically ill patients from the ED to the Intensive Care Unit can be seen in Table 1 .

Table 1: Distribution of AEs Frequencies during Transfer of Patients from the ED to the Intensive Care Unit $(n=151)$

\begin{tabular}{|l|c|c|}
\hline \multicolumn{1}{|c|}{ Variables } & F & \% \\
\hline AEs during transport & & \\
No AEs & 32 & 21.2 \\
AEs & 119 & 78.8 \\
\hline AEs Type & & \\
Non-physiological & 54 & 45.5 \\
Physiological & 33 & 27.7 \\
Combined AEs & 32 & 26.8 \\
\hline
\end{tabular}

The table shows most of the respondents who were transported experienced AEs during the transfer. The non-physiological AE was the most frequent case found.

Table 2: The Frequency Distribution of Physiological AEs Parameters during Critical Patient Transfer from the ED to the Intensive Care Unit

\begin{tabular}{|c|c|c|}
\hline Condition & $\mathbf{N}$ & $\%$ \\
\hline Systolic reduction $>20 \%$ early & 8 & 8.9 \\
\hline Systolic increase $>20 \%$ early & 6 & 6.7 \\
\hline Systolic $<90 \mathrm{mmHg}$ & 6 & 6.7 \\
\hline $\mathrm{O}_{2}$ saturation $<90 \%$ & 4 & 4.4 \\
\hline $\mathrm{RR}<8$ or $>30 \mathrm{x} /$ Minute & 9 & 10.0 \\
\hline $\mathrm{HR}<40$ or $>130 \mathrm{x} /$ minute & 9 & 10.0 \\
\hline New onset of arrhythmia & 6 & 6.7 \\
\hline Agitation & 11 & 12.2 \\
\hline Convulsions & 1 & 1.1 \\
\hline Bleeding & 2 & 2.2 \\
\hline Decreased awareness (GCS) & 7 & 8.9 \\
\hline Nausea & 12 & 13.3 \\
\hline Increased pain score & 7 & 7.7 \\
\hline Cardiopulmonary arrest & 1 & 1.1 \\
\hline Patient died & 1 & 1.1 \\
\hline Total & 90 & 100 \\
\hline
\end{tabular}

Table 2 shows the occurrence of physiological AEs. Most physiological AEs were nausea and agitation and one respondent experienced cardiopulmonary arrest and resulting in death. 
Table 3: Frequency Distribution of Non-Physiological Incident Parameters during Critical Patient Transfer from the ED to the Intensive Care Unit

\begin{tabular}{|l|c|c|}
\hline \multicolumn{1}{|c|}{ Condition } & $\mathbf{N}$ & $\mathbf{\%}$ \\
\hline Oxygen supply ran out & 2 & 1.7 \\
\hline Lost vein access device, clogged or not smooth & 18 & 15.8 \\
\hline Change in the drain position & 2 & 1.7 \\
\hline Change in NGT/OGT position & 1 & 0.9 \\
\hline Delayed > 5 minutes at the destination & 6 & 5.3 \\
\hline Required a restrain & 6 & 5.3 \\
\hline Temporary cessation therapy (infusion) & 65 & 57.0 \\
\hline Error documenting drugs & 2 & 1.7 \\
\hline The document left or not complete & 6 & 5.3 \\
\hline $\begin{array}{l}\text { Other (water humidifier entered the patient's nasal } \\
\text { cannula) }\end{array}$ & 6 & 5.3 \\
\hline Total & $\mathbf{1 1 4}$ & $\mathbf{1 0 0}$ \\
\hline
\end{tabular}

Table 3 shows that most non-physiological AEs were temporary terminations of therapy during transport followed by the discontinuity of venous access devices.

Table 4: Correlation among Age, Gender, Primary Case, Transfer Level, Conformity of Personnel to AEs during Transfers from the ED to Intensive Care Unit $(n=151)$

\begin{tabular}{|c|c|c|c|c|}
\hline Characteristics & $\mathbf{F}$ & $\%$ & $r$ & $p$ \\
\hline $\begin{array}{l}\text { Age } \\
>65 \text { years } \\
46-65 \text { years } \\
26-45 \text { years } \\
17-25 \text { years }\end{array}$ & $\begin{array}{c}45 \\
74 \\
26 \\
6\end{array}$ & $\begin{array}{c}29.8 \\
49.0 \\
17.2 \\
4.0\end{array}$ & 0.351 & $0.012 *$ \\
\hline $\begin{array}{l}\text { Gender } \\
\text { Male } \\
\text { Female }\end{array}$ & $\begin{array}{l}90 \\
61 \\
\end{array}$ & $\begin{array}{l}59.6 \\
40.4 \\
\end{array}$ & 0.249 & $0.019^{*}$ \\
\hline $\begin{array}{l}\text { Primary Case } \\
\text { Surgery } \\
\text { Internal Disease } \\
\text { Cardiovascular } \\
\text { Neurology } \\
\text { Lungs }\end{array}$ & $\begin{array}{c}17 \\
37 \\
66 \\
23 \\
8\end{array}$ & $\begin{array}{c}11.3 \\
24.5 \\
43.7 \\
15.2 \\
5.3\end{array}$ & 0.338 & 0.078 \\
\hline $\begin{array}{l}\text { Level Transfer } \\
3^{\text {rd }} \text { Level } \\
2^{\text {nd }} \text { Level }\end{array}$ & $\begin{array}{c}31 \\
120\end{array}$ & $\begin{array}{l}20.5 \\
79.5\end{array}$ & 0.224 & 0.056 \\
\hline $\begin{array}{l}\text { Conformity of } \\
\text { Transport } \\
\text { Personnel } \\
\text { Conformity } \\
\text { Non-Conformity }\end{array}$ & $\begin{array}{c}106 \\
45\end{array}$ & $\begin{array}{l}70.2 \\
29.8\end{array}$ & 0.281 & $0.005^{*}$ \\
\hline $\begin{array}{l}\text { Nursing Education } \\
\text { Diploma (D3) } \\
\text { Nurse Profession }\end{array}$ & $\begin{array}{c}142 \\
9\end{array}$ & $\begin{array}{c}94.0 \\
6.0\end{array}$ & 0.149 & 0.329 \\
\hline $\begin{array}{l}\text { Nursing Certificate } \\
\text { Basic } \\
\text { Advance }\end{array}$ & $\begin{array}{c}118 \\
33\end{array}$ & $\begin{array}{l}78.1 \\
21.9\end{array}$ & 0.112 & 0.595 \\
\hline
\end{tabular}

\section{DISCUSSION}

Intra-hospital patient transport is defined as a temporary or permanent transport inside of the hospital environment for diagnostic, therapeutic, and treatment purposes in special units (Shields, Overstreet \& Krau, 2015). Adverse events during the transport of critically ill patients are defined as any expected or unexpected event that affects patient stability during the transport consisting of team failures, equipment failures, delays, and physiological changes (Gimenez et al., 2017). According to the Conceptual Framework from World Health Organization (2009), the characteristics of patients influence incidence of adverse events. The factors affecting these situations are the patients' demographic data, the main reason being the patients' needs of treatment, and the primary diagnosis.

In this study, the most physiological AE was nausea. Based on observations in this study, most of the respondents had primary cases of a cardiovascular emergency. Nausea occurred in patient were mostly with thrombolytic administration. Besides, the travel route from the ED to the Intensive Care Cardiovascular Unit (ICVCU) must pass the elevator two times and the inter-building movement is slightly uphill. This leads to inconvenience for respondents. It is in line with Aslanabadi et al., (2018) who observed that 217 patients were administered with streptokinase therapy. The study found that the side effects of streptokinase were chest pain, hypotension, cough, and limb pain, nausea, spit-up, bronchospasm, arrhythmia, fever, hemorrhage, headache, agitation, hematuria, diarrhea, and hypoxia.

Most of the non-physiological events that occurred during transfer were temporary cessation of therapy. It indicates that the transfer assistance officer pays little attention to the importance of maintaining continuity of therapy during the transfer process. During Transfer the movement may cause Intra Venous (IV) line to be blocked, or can be lose, or is non-smooth. During the transport, patients must be carried carefully to avoid any hindrances. The mild hindrance may cause displacement of intravenous access that can potential turns into serious problems for the patients (Knight et al., 2015).

The ages group in this study are divided into 16-25 years, $26-45$ years, $46-65$ years, and $>65$ years. This study is in line with the results of previous studies stating that age affects undesirable events during the transfer of critically ill patients in the ICU (Harish et al., 
2016). The functional consequence theory states that as a consequence of increasing age causes decrease in biological functions (Miller, 2012). This will go hand in hand with increasing age (aging process) (Standhope \& Lancaster, 2016).

Male was significantly related to the adverse events during the transfer of critical patients from the emergency department to the intensive care unit. This study is not in line with the study by Farnoosh et al., (2018) and Kue et al., (2011) showing that gender is not related to adverse events during the transport of critically ill patients in the hospital. According to the researchers' analysis, there was a correlation between gender and the adverse events during the transfer of patients indicating that the $90(59.5 \%)$ respondents were male.

The suitability of the transport officer in this study can be seen from the number and composition of the transfer assistance team. Observation results show that all $151(100 \%)$ respondents about $106(70.2 \%)$ respondents were transferred by inappropriate teams. The results of this study are in line with Yang et al., (2017) which indicated that there is a significant relationship between the transfer accompanied by a doctor or not accompanied by a doctor. The transfer team is recommended to consist of doctors with airway management experience, trained critical nurses, and technicians trained in mechanical ventilation equipment (Decrucq et al., 2013; Quenot et al., 2012). The multidisciplinary transfer team is effectively able to overcome potential problems that occur during the transfer of critically ill patients (Kue et al., 2011; Kulshrestha and Singh, 2016). There is also a need for additional workers to assist the nurse during transport
(Blay et al., 2017).

There is no relationship between the education and training of transfer companion nurses and the occur of adverse events. Most of the respondents were accompanied by nurses with a Diploma in nursing with basic practical training. Transfer assistance staff should be trained, competent, experienced in transferring critically ill patients, and certified transfer training along with Advance Cardiac Life Support (ACLS), airway management, and critical care training (Fanara et al., 2010; Kulshresta and Singh, 2016). Based on the observation it can be said that the nurses in charge of transfer along with their assistants in each shift are the same people which may lead to making repeated mistakes.

\section{CONCLUSION}

The AEs during the transport of critically ill patients from the ED to the Intensive Care Unit are still quite high. The most frequent AE is non-physiological AE, i.e. the cessation of therapy temporarily. There is a relationship among age, sex, and the suitability of transfer assistants with AEs during the transfer of patients in the hospital. The transport companion officer should ensure that the venous access device and device attached to the patient are functioning properly during the transfer within the hospital.

\section{Conflict of Interests}

The authors declare that they have no conflict of interest.

\section{ACKNOWLEDGEMENT}

Thanks to Mr. Ahsan, Mrs. Yulian Wiji Utami, and Mrs. Septi for their contribution to this study.

\section{REFERENCES}

Aslanabadi, N., Safaie, N., Talebi, F., Dousti, S. \& Entezari-maleki, T. (2018). The streptokinase therapy complications and its associated risk factors in patients with acute st- elevation myocardial infarction. Iranian Journal of Pharmachetical Research, 17(Special issue), pp 53-63.

Bergman, L.M., Pettersson, M.E., Chaboyer, W.P., Carlström, E.D. \& Ringdal, M.L. (2017). Safety hazards during intrahospital transport: A prospective observational study. Critical Care Medicine, 45(10), pp 1043-1049.

Blay, N., Roche, M.A., Duffield, C. \& Gallagher, R. (2017). Intrahospital transfers and the impact on nursing workload. Journal of Clinical Nursing, 26(23-24), pp 4822-4829.

Choi, H.K., Shin, S. Do, Ro, Y.S., Kim, D.K., Shin, S.H. \& Kwak, Y.H. (2012). A before- and after-intervention trial for reducing unexpected events during the intrahospital transport of emergency patients. American Journal of Emergency Medicine, 30(8), pp 1433-1440. 
Decrucq, E.P.E., Poissy, J., Favory, R., Nseir, S., Onimus, T., Guerry, M.J., Durocher, A. \& Mathieu, D. (2013). Adverse events during intrahospital transport of critically ill patients: Incidence and risk factors. Annals of Intensive Care, 3(1), pp 1-10.

Fanara, B., Manzon, C., Barbot, O., Desmettre, T. \& Capellier, G. (2010). Recommendations for the intra-hospital transport of critically ill patients. Critical Care, 14(3), pp 1-10.

Farnoosh, L., Hossein-nejad, H., Beigmohammadi, M. \& Seyed-Hosseini-Davarani, S.-H. (2018). Preparation and implementation of intrahospital transfer protocol for emergency department patients to decrease unexpected events. Advanced Journal of Emergency Medicine, 2(3), pp 27-29.

Gimenez, F.M.P., Camargo, W.H.B. De, Gomes, A.C.B., Nihei, T.S., Andrade, M.W. M., Valverde, M. L.D.A.F.S., Campos, L.D.E.D.S., Grion, D.C., Festti, J. \& Grion, C.M. C. (2017). Analysis of adverse events during Intrahospital transportation of critically ill patients. Critical Care Research and Practice, 2017(2), pp 1-7.

Harish, M.M., Janarthanan, S., Siddiqui, S.S., Chaudhary, H.K., Prabu, N.R., Divatia, J.V. \& Kulkarni, A.P. (2016). Complications and benefits of intrahospital transport of adult intensive care unit patients. Indian Journal of Critical Care Medicine, 20(8), pp 448-452.

Jennings, B. M., Sandelowski, M. \& Higgins, M.K. (2013). Turning over patient turnover: An ethnographic study of admissions, discharges, and transfers. Research in Nursing and Health, 36(6), pp 554-566.

Jia, L., Wang, H., Gao, Y., Liu, H. \& Yu, K. (2016). High incidence of adverse events during intra-hospital transport of critically ill patients and new related risk factors: A prospective, multicenter study in China. Critical Care, 20(1), pp 1-14.

Jiang, X.X., Wang, J., Zhang, W., Wang, X.J. \& Meng, X.H. (2016). Safe transport combined with prospective nursing intervention in intra-hospital transport of emergency critically ill patients. International Journal of Clinical and Experimental Medicine, 9(7), pp 13166-13171.

Jones, H. M., Zychowicz, M.E., Champagne, M. \& Thornlow, D.K. (2016). Intrahospital transport of the critically ill adult: A standardized evaluation plan. Dimensions of Critical Care Nursing, 35(3), pp 133-146.

Knight, P.H., Maheshwari, N., Hussain, J., Scholl, M., Hughes, M., Papadimos, T.J., Guo, W. A., Cipolla, J., Stawicki, S.P. \& Latchana, N. (2015). Complications during intrahospital transport of critically ill patients: Focus on risk identification and prevention. International Journal of Critical Illness and Injury Science, 5(4), pp 256-264.

Kue, R., Brown, P., Ness, C. \& Scheulen, J. (2011). Adverse clinical events during intrahospital transport by a specialized team: A preliminary report. American Journal of Critical Care, 20(2), pp 153-162.

Kulshrestha, A. \& Singh, J. (2016). Inter-hospital and intra-hospital patient transfer: Recent concepts. Indian Journal of Anaesthesia, 60(7), pp 451-457.

Miller, C.A. (2012). Nursing for wellness in older Adults. $6^{\text {th }}$ edition. USA: Lippincott Williams \& Wilkins.

Quenot, J., Milési, C., Cravoisy, A., Capellier, G., Mimoz, O., Fourcade, O. \& Gueugniaud, P. (2012). Intrahospital transport of critically ill patients (excluding newborns) recommendations of the Société de Réanimation de Langue Française (SRLF), the Société Française d ' Anesthésie et de Réanimation (SFAR), and the Société Française de Médecine d. Annals of Intensive Care, 2(1), pp 1-6.

Ringdal, M., Chaboyer, W. \& Warrén Stomberg, M. (2016). Intrahospital transports of critically ill patients: Critical care nurses' perceptions. Nursing in Critical Care, 21(3), pp 178-184.

Salt, O., Akpınar, M., Sayhan, M., Örs, F., Durukan, P. \& Baykan, N. \& Kavalcı, C. (2020). Intrahospital critical 
patient transport from the emergency department. Archives of Medical Science, 16(2), pp 337-344.

Shields, J., Overstreet, M. \& Krau, S.D. (2015). Nurse knowledge of intrahospital transport. Clinical Nursing, 50, pp $293-314$.

Standhope, M. \& Lancaster, J. (2016). Publichealth nursing population centered health care in the community. $9^{\text {th }}$ edition, Issue 2009). Elsevier/Mosby.

Stang, A.S., Wingert, A.S., Hartling, L. \& Plint, A.C. (2013). Adverse events related to emergency department care: A systematic review. PLoS ONE, 8(9), pp 1-7.

Tolentino, J.C., Schadt, J., Bird, B., Yanagawa, F.S., Zanders, T.B. \& Stawicki, S.P. (2018). Adverse events during intrahospital transfers: Focus on patient safety. Vignettes in Patient Safety, 3(2), pp 107-124.

World Health Organization (WHO) (2009). Conceptual framework for the international classification for patient safety. IEEE Aerospace Conference Proceedings, January, pp 7-11.

Yang, S.H., Jerng, J.S., Chen, L.C., Li, Y.T., Huang, H.F., Wu, C.L., Chan, J.Y., Huang, S. F., Liang, H.W. \& Sun, J.S. 